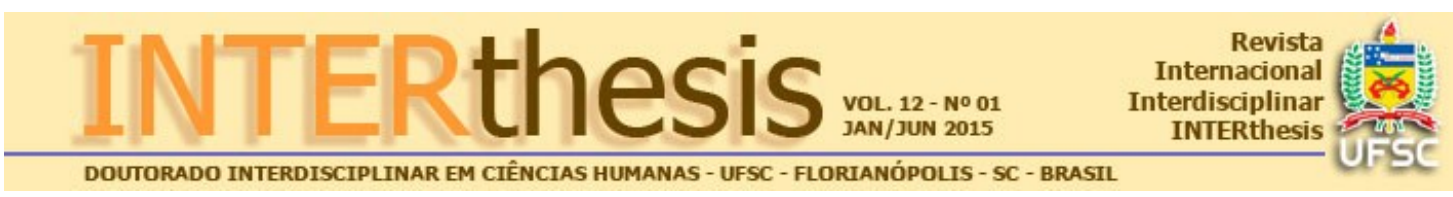

\title{
O QUE O MERCADO NÃO MATA: UMA ANÁLISE DA MORALIDADE ESPECISTA
}

\section{E A ECONOMIA}

\author{
Wesley Felipe de Oliveira ${ }^{1}$ \\ Alessandro Pinzani ${ }^{2}$
}

\section{Resumo:}

Neste trabalho analisamos a relação entre a moral e a economia a partir da discussão suscitada por Michael Sandel acerca dos limites morais do mercado. Sandel investiga de que maneira os valores morais estão sendo cada vez mais inseridos dentro da lógica do mercado econômico pautada pelo lucro. Mais precisamente, investigamos de que maneira a moralidade especista, que fundamenta a exclusão dos animais do âmbito da comunidade moral humana, está vinculada à lógica de mercado, inserindo e mantendo os animais não humanos dentro de um sistema que busca lucro monetário por meio da exploração e comercialização deles. Defendemos que, embora a economia tenha uma influência significativa para determinar certas práticas morais, o oposto também acontece, isto é, a moralidade também pode exercer uma influência sobre o mercado e ditar os seus limites sobre aquilo que pode ou não pode ser colocado dentro da lógica do lucro econômico. A superação da moralidade especista a partir de propostas éticas que visam incluir seres sencientes na esfera de ação moral dos seres humanos, levando, portanto, seus interesses em consideração, é capaz, portanto, de levar a uma desvinculação dos animais da lógica de mercado.

Palavras-chave: Economia. Especismo. Moralidade. Senciência.

\section{INTRODUÇÃO}

O objetivo do presente artigo é analisar as práticas econômicas ligadas à lucrativa exploração e morte de animais não-humanos. Utilizaremos as reflexões do filósofo Michael Sandel acerca dos limites morais do mercado, aplicando-as à análise das mercadorias cuja matéria prima se caracteriza pelo desmembramento dos corpos dos animais, transformados assim em produtos comercializáveis: pedaços de carnes, couro, peles, artigos decorativos; mas consideraremos também

\footnotetext{
${ }^{1}$ Doutorando na área de Ética e Filosofia Política pelo Programa de Pós-Graduação em Filosofia da Universidade Federal de Santa Catarina, Florianópolis, SC, Brasil. E-mail: wesley.filosofia@hotmail.com

2 Doutor em Filosofia pela Universität Tübingen. Professor de Ética e Filosofia Política do Departamento de Filosofia e do Programa de Pós-Graduação em Filosofia da Universidade Federal de Santa Catarina, Florianópolis, SC, Brasil. E-mail: Alessandro@cfh.ufsc.br
} 
seu uso no entretenimento, em testes científicos e em demais atividades. Defendemos, neste artigo, que de acordo com Sandel o mercado exerce uma forte influência sobre a moralidade, sendo capaz de corromper ou degradar determinados bens e valores humanos. No entanto, consideramos que além da moralidade ser influenciada pelos ditames do mercado, em alguma medida ela também exerce sua influência no mercado, uma vez que o mercado existe, entre outras razões, para atender as necessidades e satisfazer os desejos e preferências dos seres humanos. Nesse sentido, pode-se compreender que o mercado é capaz de se modificar e se adequar aos novos padrões morais que modificam os hábitos de consumo. Moralidade e economia não são duas coisas distintas e incomunicáveis, mas antes, duas áreas que exercem, em alguma medida, uma influência recíproca. A partir desse entendimento, defendemos que a valoração moral da vida animal e a superação do preconceito especista pode exercer uma forte influência no mercado, desvinculando, portanto, seres vivos sencientes da lógica de um mercado que lucra com sua exploração, a exemplo do que ocorreu em séculos passados com a desvinculação de seres humanos escravizados.

\section{A ECONOMIA ACIMA DE TUDO?}

Em seu livro "O Que o Dinheiro Não Compra: os limites morais do mercado", publicado em 2012, assim como nas homônimas aulas, apresentadas em 1998 no âmbito das Tanner Lectures on Human Value, o filósofo norte-americano Michael Sandel toma como ponto de partida a seguinte pergunta: "Há alguma coisa que o dinheiro não possa comprar?" (SANDEL, 1998, p. 90, tradução nossa), e sua resposta não muito otimista é a de que, infelizmente, há cada vez menos coisas que não estão sendo colocadas dentro da lógica de mercado. Atualmente, as práticas mercadológicas estenderam seu alcance em quase todas as esferas da vida. Sandel cita em seu livro inúmeros casos que exemplificam tais práticas na vida cotidiana e nas relações humanas em diversas áreas: na saúde, por exemplo, com casos de médicos que vendiam bebês que seriam abortados, com a comercialização de órgãos humanos, com o oferecimento de dinheiro para mulheres viciadas em drogas se esterilizarem, com o fenômeno da "barriga de aluguel", etc. $\mathrm{Na}$ esfera da cidadania, são mencionadas práticas de venda de votos bem como o emprego de 
estrangeiros no serviço militar em lugar de soldados nacionais. Com isso, Sandel compreende que vivemos numa era na qual houve uma transição de uma economia de mercado para uma sociedade de mercado. Nesse sentido, entende-se que:

[...] uma economia de mercado é uma ferramenta - valiosa e eficaz - de organização de uma atividade produtiva. Uma sociedade de mercado é um modo de vida em que os valores de mercado permeiam cada aspecto da atividade humana. É um lugar em que as relações sociais são reformatadas à imagem do mercado (SANDEL, 2012, p. 16).

Sandel é atento ao modo como o mercado atinge as relações sociais humanas e enfatiza o quanto ele é capaz de exercer forte influencia nas relações, decisões e ações humanas, ao se inserir, por exemplo, nas esferas da vida em que bens não materiais são colocados à troca ou à venda, mas em condições econômicas desiguais, assim que tais transações acabam não ocorrendo de maneira legitimamente voluntária pelas partes envolvidas, como os economistas mainstream sugerem. Um homem pobre que vende seu rim para um homem rico e doente para poder comprar com o dinheiro recebido alimentos para a sua família configura um tipo de relação econômica que se dá de modo coercitivo, ou seja, não verdadeiramente voluntário ou livre. O contexto e a posição social dos dois indivíduos torna a relação desigual. Nesses casos, as pessoas se submetem a relações comerciais e de trabalho que são injustas, mas somente porque esta é a única forma de conseguir dinheiro para adquirir bens e produtos essenciais para sua sobrevivência.

Por outro lado, Sandel também é atento ao efeito degradante que a lógica de mercado exerce sobre determinados bens e valores tanto morais quanto cívicos que são corrompidos, tendo seu verdadeiro sentido diminuído, quando comprados e vendidos, ainda que em condições que se mostrem justas e não coercitivas. Para Sandel:

Se a venda de partes do corpo humano é intrinsicamente degradante, uma violação da santidade do corpo humano, então a venda de rins seria errada para ricos e pobres. Essa objeção se manteria mesmo sem o efeito coercitivo da pobreza (SANDEL, 1998, p. 94).

Entendemos, no entanto, que não apenas o mercado pode influenciar a moralidade, inserindo-se nas ações e escolhas dos indivíduos, como bem analisa Sandel, mas, por mais que esse fator econômico seja forte e muitas vezes até mesmo determinante, em alguns casos é possível afirmar que essa relação é invertida, isto é, a moralidade também pode exercer sua influência sobre o mercado, 
fazendo com que certas coisas (ainda que poucas, como reconhece Sandel) fiquem fora desta lógica de mercado que coloca um valor monetário sobre tudo e todos.

A economia escravocrata nas Américas e a abolição da escravatura são o melhor exemplo que vêm à mente para ilustrar isto. Por um lado, índios e negros usados como escravos na produção de bens materiais demonstram quanto relações sociais de cunho racista sempre estiveram em estreita relação com o mercado. Por outro lado, o gradual reconhecimento do valor da vida dos seres humanos tomados como escravos foi um importante fator moral (ainda que não o único, pois fatores econômicos também estavam envolvidos) que impulsionou a revisão das relações entre brancos e negros no que diz respeito ao trabalho escravo. Atualmente, submeter um ser humano a um regime de escravidão ou em condições coercitivas de trabalho é uma clara violação dos direitos humanos. Fazer isso hoje em dia, para usar os termos de Sandel, é corromper o valor e o respeito pela vida humana.

\section{MORALIDADE ESPECISTA E ECONOMIA}

Passemos agora a analisar a esfera da relação dos seres humanos com as outras espécies de vida animal do ponto de vista da relação entre moralidade e mercado. De acordo com Peter Singer, a consciência moral dominante na sociedade no que diz respeito à relação com os animais não humanos pode ser definida como especista, uma vez que tanto nas práticas morais privadas quanto nas instituições sociais e políticas se confere peso e importância maiores aos interesses humanos em detrimento dos interesses semelhantes dos animais (Cf. SINGER, 2004; 1989). Essa desigualdade na consideração de interesses semelhantes se dá pelo fato de os animais pertencerem a espécies diferentes da humana, ainda que compartilhem características que prezamos e protegemos porque as consideramos moralmente importantes para todos os seres humanos, principalmente o interesse fundamental em não sentir dor e sofrimento. É em razão da moralidade especista que prevalece a ideia de que os animais seriam meras propriedades dos seres humanos e de que seus interesses, ainda que semelhantes aos nossos, importam menos em razão da diferença de espécie. Esta é a mesma lógica por detrás do preconceito racial escravocrata que entendia que os interesses semelhantes dos negros eram menos importantes do que os dos brancos, simplesmente por pertencerem a raças 
diferentes, e que isso justificaria que os brancos os tornassem sua propriedade por meio da força.

No padrão moral especista, que norteia as relações humanas com os demais animais, estes últimos, tal como os humanos no período de escravidão, são vistos como meros produtos do mercado, matérias primas ou mercadorias vivas, sobre as quais os seres humanos exercem um domínio que Ihes permite comprá-los e vendêlos, para explorá-los, manipulá-los, transformá-los e usá-los conforme os mais diversos interesses humanos em questões de gosto, vestuário, entretenimento, conhecimento científico, esporte, etc. - interesses que são satisfeitos dentro de um sistema de mercado, que "oferece" os animais para os que desejarem consumi-los e servir-se deles nos mais variados modos e práticas. Nesse sentido, para atender estes interesses formou-se nos últimos quarenta anos uma forte estrutura política e econômica globalizada voltada a garantir a criação e o abate dos animais de consumo (no ano de 2006 se chegou à média anual de 60 bilhões de animais abatidos) e a reservar o acesso à água potável e a mais de $75 \%$ dos grãos e cereais produzidos no planeta (além de outras necessidades como medicamentos e infraestrutura) para uso exclusivo da indústria da criação animal ${ }^{3}$. Isso demonstra de que maneira esse mercado (o agronegócio) interfere diretamente nos bens essenciais para a vida humana para satisfazer um interesse específico, subtraindo a outros usos amplas áreas de lavoura, água, alimentos de alto teor nutritivo (que são produzidos e destinados para alimentar animais a serem abatidos), além de muitos outros recursos financeiros e energéticos. E nesse quadro, há cerca de um bilhão de seres humanos que vivem em miséria e às margens do acesso a esses bens - 0 que demonstra uma corrupção dos valores humanos acerca da justiça social e da justiça distributiva. Este sistema econômico e político é eficiente em alimentar sessenta bilhões de animais abatidos por ano, mas ineficiente para sanar as necessidades nutricionais e infraestruturais mais básicas da população humana.

Não é difícil encontrar outros fatos que demonstrem como a vida animal acabou sendo submetida à lógica de mercado. Citaremos algumas práticas (mais ou menos comuns) que envolvem os animais e que são regulamentadas pelas leis:

\footnotetext{
${ }^{3}$ Conforme Relatório FAO Livestock's Long Shadow: environment issues and options, Food and Agriculture Organization of the United Nations, 2006. Disponível em: http://www.fao.org/docrep/010/a0701e/a0701e00.HTM\#sthash.FRAGDo4l.dpuf. Acesso em: 05 Jan. 2013.
} 
pagar para provar o sabor da carne de um animal exótico, comercializar animais de estimação e servir-se de pet shops para cuidar de sua aparência, criar e vender camundongos geneticamente modificados para pesquisas científicas que chegam a custar até 50 mil dólares. ${ }^{4}$ Isso sem contar as práticas que ocorrem à margem ou fora da lei: governos municipais que oferecem de $\mathrm{R} \$ 5$ a $\mathrm{R} \$ 10$ para os munícipes capturarem e exterminarem animais de rua $^{5}$, pessoas que pagam para assistir rinhas de galos ou cães, tráfico de animais silvestres e exóticos e tantos outros casos.

Sandel discute só alguns casos envolvendo as relações humanas com os animais. Ele analisa, em particular, os incentivos de mercado criados para proteger algumas espécies ameaçadas de extinção, como no caso do rinoceronte negro. Os fazendeiros de alguns países africanos podem vender aos caçadores o direito de abater uma quantidade limitada e controlada de animais. Isso resulta na criação de um incentivo monetário para que estes animais sejam criados e protegidos, afastando os caçadores ilegais. ${ }^{6} \mathrm{Na}$ África do Sul, um dos países onde essa prática foi regulamentada, a população de rinocerontes está começando a se recompor, enquanto que no Quênia, onde ela é proibida, a população de rinocerontes continua diminuindo drasticamente (Cf. SANDEL, 2012, p. 80-81). A primeira caça legalmente autorizada custou US\$150.000, que foi paga por um cidadão norte americano. Em janeiro de 2013, o valor pago para caçar um rinoceronte na Namíbia foi de US\$ 350.000 (equivalente à $\mathrm{R} \$$ 822.000), pago por um caçador membro do Dallas Safari Club, localizado no Texas e que serve de intermediário entre o caçador e o Estado da Namíbia. Parte do dinheiro arrecadado será usado para a preservação dessa espécie, garantindo assim que mais animais sejam criados para serem caçados controladamente ${ }^{7}$.

4 http://noticias.uol.com.br/inter/reuters/2002/03/25/ult27u20538.jhtm. Acesso em: 05 Jan. 2013.

5 http://www.anda.jor.br/04/06/2013/prefeito-paga-r-10-para-municipes-para-captura-de-caes-emsanta-cruz-do-arari-pa. Acesso em: 05 Jan. 2013.

${ }^{6}$ Ainda que isso possa ser considerado uma ação louvável, ela não foge da lógica especista. $O$ especismo eletivo, conforme definido por Sônia T. Felipe, consiste em defender um determinado animal ou sua espécie, que é escolhida ou eleita para receber todas as proteções morais contra maus tratos e atos que Ihes tirem a vida, quando este animal Ihe inspira algum sentimento de simpatia ou compaixão, ou ainda interesse econômico enquanto que outras espécies não recebem essa proteção moral. "[...] passamos a defender os animais escolhendo os que julgamos mais adequados à expressão de nossa necessidade afetiva, estética, econômica, etc. Elegemos, então certos animais, de acordo com nossa predileção. [...] Não fugimos, desse modo, nem do antropocentrismo, nem do especismo" ( FELIPE, 2007, p. 146).

7 Ainda que pareça uma novidade, esta prática já existe por décadas nos conhecidos locais chamados de "pesque-pague", onde peixes são criados com a finalidade de serem pescados e os

R. Inter. Interdisc. INTERthesis, Florianópolis, v.12, n.1, p.01-15, Jan-Jun. 2015 
Acerca deste caso, Sandel observa que:

[...] do ponto de vista da lógica econômica, a solução de mercado parece perfeitamente vitoriosa. Melhora a situação de algumas pessoas e não prejudica ninguém. Os fazendeiros ganham dinheiro, os caçadores têm uma oportunidade de caçar e abater uma formidável criatura, e uma espécie ameaçada é salva do risco de extinção. Quem haveria de se queixar? (SANDEL, 2012, p. 81).

A possível objeção a tal prática, observa Sandel, "vai depender do prestígio moral do esporte da caça" (SANDEL, 2012, p. 81), isto porque, os caçadores entendem que existe uma legitimidade em seu esporte, alegando certo valor moral, que implica até mesmo respeito e reverência, em caçar e abater um animal forte e poderoso. Por outro lado, os que condenam tal prática entendem que esta não é uma forma legítima de se valorizar e respeitar um ser vivo senciente, ou seja, capaz de sentir dor, sofrimento e até mesmo a desagradável sensação do medo. A preservação da espécie pode até ter algo moralmente aceito, "mas o caráter condenável das caçadas neutraliza os efeitos benéficos em matéria de conservação natural" (SANDEL, 2012, p. 81).

Entendemos que a questão é muito mais complexa e envolve algo mais profundo do que a legitimidade moral do esporte da caça. Envolve, antes de tudo, a legitimidade do status moral do objeto desse esporte, neste caso, um animal. Ela atinge diretamente a questão da legitimidade do presumido direito dos seres humanos de recrear-se provocando dor e sofrimento e causando a morte violenta de animais sencientes. Se o prazer, a dor e o sofrimento possuem um valor moral para os seres humanos (razão esta que leva a cada um de nós a nos protegermos de atos que nos causem dor e privação do prazer), não deveríamos, como propôs Peter Singer, estender, por uma questão de coerência moral com os princípios que defendemos, a mesma proteção contra a dor, o sofrimento e a morte também aos animais, uma vez que estes são capazes de vivenciar tais experiências? É apenas em razão de nosso especismo que toleramos o que é feito aos animais e, todavia, condenamos os mesmos atos quando praticados em seres humanos.

Nesse sentido, a questão se amplia e se aplica não somente à prática esportiva da caça, mas sim, a todas as demais formas de incorporação da vida animal à lógica de mercado, que vem a caracterizar-se, neste caso, como um

pescadores pagam apenas pelo que conseguirem pegar. A única coisa que difere da caça legalizada de rinocerontes é a espécie de animal caçada.

R. Inter. Interdisc. INTERthesis, Florianópolis, v.12, n.1, p.01-15, Jan-Jun. 2015 
sistema de obtenção de lucro por meio da exploração dos corpos e da vida dos animais não-humanos, principalmente das espécies utilizadas para alimentação, vestuário e testes científicos - finalidades para as quais os mais diversos animais são criados em ritmo e escala industrial para se tornarem diretamente mercadorias (como no caso do consumo de carne) ou para dar vida a inúmeros produtos (como o leite e seus derivados, vários artigos de vestuário, como calçados de couro, roupas de lã, estofados), ou para servir em experimentos realizados pelas pesquisas científicas e pela indústria farmacêutica ou em testes da indústria cosmética.

Ainda que animais não-humanos nunca tenham desfrutado de um status moral plenamente positivo no que diz respeito à proteção contra maus tratos e morte causados por ações humanas, e tampouco tenham sido respeitados de modo significativo nas sociedades, podemos entender que foi com a criação industrial intensiva e maciça de animais, que tomou um forte impulso no período pós-guerra, que os animais passaram a estar mais presentes dentro da lógica do mercado. Mais do que nunca, os animais passaram a ser meros produtos, chegando ao auge de sua incorporação como propriedade humana e sendo, portanto, transformados pela indústria de consumo em uma mercadoria. Passaram a ser criados (ou produzidos) e tratados assim como quaisquer outras commodities. São "colhidos" para o abate tal como é colhido o arroz ou o milho. Foram, definitivamente, introduzidos na mesma lógica da linha de montagem fordista, embora neste caso específico, podemos falar em "linha de desmontagem", uma vez que seus corpos são desfragmentados e desmembrados. Para usar uma linguagem industrial: cada animal, tomado como mera máquina, tem suas peças (membros e órgãos) separadas e desmontadas por um operário responsável por uma parte específica com cada trabalhador executando um único e mesmo processo durante todas as horas de sua jornada de trabalho. $O$ objetivo desse método não é outro senão o de desmembrar quanto mais corpos de animais no menor período de tempo, agregando valor a cada membro a ser consumido e obtendo mais lucro com um tempo e custo menor, resultando, portanto, em um eficiente sistema de produção.

Conforme bem nos lembra Sandel, "os mercados não julgam os desejos que atendem" (SANDEL, 2012, p. 84), ou seja, eles apenas atendem os interesses e as preferências das pessoas, sem acrescentar nenhuma avaliação moral à avaliação mercadológica dos desejos. Ainda que tal posição dos economistas sempre tenha 
sido um assunto questionável, a maioria deles ainda insiste em manter a distinção entre economia e ética, assim como aquela entre a lógica de mercado e a lógica da moral, tratando as duas esferas como se fossem incomunicáveis. (Cf. SANDEL, 2012, p. 88). Por essa razão, os interesses e as preferências humanas buscam sempre ser satisfeitas pelo mercado. Se há quem tem interesse em pagar quase um milhão de reais para se divertir abatendo um animal selvagem na África, haverá empresas especializadas e regulamentadas pelos governos que se proponham a oferecer esse serviço. Se há quem deseja comer carne de tartaruga, haverá quem cobre um preço para criar em cativeiro ou caçar este animal e oferecê-lo ao seu comprador. Se há quem deseja pendurar uma cabeça de leão em sua sala de estar, haverá sempre quem ofereça esse serviço de caçar o animal.

Ainda que a exploração animal não seja uma invenção do sistema capitalista, mas conste já nos primeiros registros da história da humanidade, é notável, no entanto, o quanto essa exploração se tornou mais concreta e intensa no sistema de mercado atual. Isso suscitou definitivamente a introdução da questão dos animais não-humanos nos debates éticos e políticos a partir de obras como Libertação Animal, de Peter Singer ${ }^{8}$. Neste livro, o autor defende a inclusão dos animais na comunidade moral humana, conferindo-lhes o direito a terem seus interesses em não sentir dor e sofrimento levados em consideração em pé de igualdade com o semelhante interesse humano. É a partir do critério da senciência, muito mais amplo e inclusivo, que Singer busca ampliar o alcance das ações humanas, superando assim o especismo e as ações danosas que dele resultam para a vida animal.

A superação do especismo provoca diretamente uma maior valorização, no sentido moral e não econômico, das experiências da vida animal, e, portanto, uma desvinculação dos animais não-humanos da lógica de mercado. Através dessa mudança de paradigma moral, pela qual somos levados a compreender que os animais não são meras máquinas insensíveis, mas sim, seres capazes de sentir dor e de experimentar conscientemente os sofrimentos derivados das privações de uma vida destituída de sua liberdade física, se torna possível colocar um limite moral à

\footnotetext{
${ }^{8}$ Ver também: REGAN, Tom. The Case for Animals Right. Berkeley: University of California Press, 1985. RYDER, Richard. The Political Animal: the conquest of speciesism: London: McFarland, 1998. LINZEY, Andrew. Animal Rights. London: SCM Press, 1976; Animal Theology: Urbana and Chicago: University of Illinois Press, 1994. FRANCIONE, Gary. Introdução aos Direitos Animais. Trad: Regina Rheda. Campinas, SP: Editora da Unicamp, 2013.
}

R. Inter. Interdisc. INTERthesis, Florianópolis, v.12, n.1, p.01-15, Jan-Jun. 2015 
comercialização exploratória de animais, que os toma meras propriedades humanas, transformadas em mercadorias com valor instrumental, isto é, como meio para gerar lucro. Ainda que tal ideia pareça ingênua ou ilusória, a superação da moralidade antropocêntrica especista compartilha de características semelhantes as dos movimentos que buscavam o fim do etnocentrismo racial com o reconhecimento de que este representava uma relação de poder opressiva, e que defendiam a desvinculação do conceito de propriedade em relação a seres vivos conscientes, autoconscientes e sencientes (os escravos), a valorização moral da vida e da liberdade e o reconhecimento da existência de interesses no outro, atacando, ao mesmo tempo, um sistema econômico, político, moral e social sustentado na escravidão. Tais características tornam a ideia de limitar a relação do mercado com a exploração animal algo possível de se concretizar.

Em certa medida, foi a crescente superação ao longo do tempo do preconceito racial que incentivou a desvinculação dos seres humanos da lógica comercial escravocrata, ainda que juntamente com as razões abolicionistas houvesse também razões ligadas a fatores econômicos, como a situação na qual se encontravam metrópoles e colônias, a qual começou a tornar inviável e não lucrativa a manutenção de um sistema escravocrata. Mas o preconceito racial presente na ética das sociedades passadas sustentou a escravidão e a comercialização de humanos do mesmo modo em que ainda hoje a moralidade especista fundamenta a inclusão dos animais dentro da lógica de mercado ${ }^{9}$. Ora, como não aceitamos que seres humanos sejam forçados a trabalhar para garantir o sustento econômico de outro ser humano de outra classe ou raça, e como também não aceitamos que humanos sejam criados para que seus órgãos possam depois ser retirados e comercializados, já que isso transgride visivelmente os direitos humanos e a integridade física e mental destes indivíduos, parece lógico e possível que, ao compreendermos que os animais também são seres conscientes, autoconscientes e

\footnotetext{
${ }^{9}$ Quando afirmamos que a moralidade influencia o mercado, não excluímos dessa hipótese a força que o mercado, por sua vez, também exerce sobre a moralidade, a fim de manter esta mesma atitude especista, afastando dos consumidores o conhecimento acerca das reais condições nas quais vivem os animais que são comercializados para consumo. Comerciais como os que foram realizados em 2013 pelo McDonalds ou pela empresa brasileira de carnes Friboi e que demonstram que suas carnes provêm de animais criados dentro de padrões de bem-estar animal que seriam moralmente aceitáveis, embora ainda questionáveis, são o resultado do questionamento moral levantado pelos consumidores acerca do sofrimento dos animais, de seus direitos morais, assim como das condições de trabalho nas fazendas e nos abatedouros. Isso levou a uma reação imediata dessas empresas, na tentativa de encobrir as denúncias de sofrimento animal feitas por ativistas dos direitos animais.
}

R. Inter. Interdisc. INTERthesis, Florianópolis, v.12, n.1, p.01-15, Jan-Jun. 2015 
sencientes, dotados de capacidades e interesses que se assemelham e que são compartilhadas com os seres humanos, passemos estranhar a prática de criar animais e desmembrá-los para comercializar suas partes para diversos tipos de uso e consumo por parte de seres humanos.

O que queremos enfatizar com essa análise comparativa é justamente que há, em alguma medida, uma relação entre a economia e a moralidade, ainda que muitos economistas rejeitem essa relação ${ }^{10}$. As mudanças de paradigmas do status moral dos humanos implicaram em mudanças na visão econômica que submetia os humanos à lógica de mercado, limitando assim a inserção de seres humanos em transações comerciais ou a autorização do comércio de mercadorias produzidas em condições de trabalho injustas ou escravagistas. Obviamente, muitos bens e valores humanos continuam sendo regulados pelo mercado, como destaca Sandel, mas ao menos em alguns casos, como o da escravidão, a lógica de mercado encontrou um limite moral.

Isso demonstra que, de alguma forma, tal como ocorreu com os seres humanos, a questão dos animais também é um desdobramento de ordem moral e política, e não meramente econômica, sendo possível que passe por uma transformação que limite as ações e os interesses econômicos dos seres humanos sobre os animais, tornando injustificável o comércio de produtos cuja matéria prima ou cuja forma de produção envolva em algum estágio o sofrimento e a morte de animais.

Para Sandel:

[...] quando decidimos que determinados bens podem ser comprados e vendidos, estamos decidindo, pelo menos implicitamente, que podem ser tratados como mercadorias, como instrumentos de lucro e uso. Mas, nem todos os bens podem ser avaliados dessa maneira (SANDEL, 2012, p. 15).

A integridade física e mental de um ser vivo senciente, autoconsciente de sua liberdade, e o entendimento por parte da comunidade moral humana de que a vida animal é um bem que the é próprio, são coisas que deveriam escapar da lógica de mercado, tal como o é quando se trata de um ser humano. Tais coisas vão além da esfera de bens matérias. É por essas (e outras) razões que a escravidão humana é entendida como algo ultrajante, por tratar seres vivos como mercadorias colocadas à

${ }^{10}$ A economia "simplesmente não lida com a moralidade", explicam Levitt e Dubner. "A moralidade representa a maneira como gostaríamos que o mundo funcionasse, e a economia representa a maneira como ele de fato funciona" (SANDEL, 2012, p. 88).

R. Inter. Interdisc. INTERthesis, Florianópolis, v.12, n.1, p.01-15, Jan-Jun. 2015 
venda para serem usadas por outros seres humanos. Esta é uma prática que corrompe os valores humanos, diria Sandel, e degrada as relações humanas ao comercializar certos bens e valores. Do mesmo modo, tratar bebês e crianças como commodities, ou seja, como algo que pode ser comercializado ou leiloado, degrada e corrompe os valores que os tomam seres humanos vulneráveis e merecedores de cuidado, carinho e respeito. Crianças e adultos negros não são mais colocados à venda no mercado e quando notícias sobre trabalhos forçados, comercialização de órgãos ou vendas de bebês vêm a conhecimento público, é notável o desconforto moral que isso provoca na sociedade, "[...] mesmo que os compradores não maltratem as crianças compradas, a existência de um mercado de crianças estaria expressando e promovendo uma maneira errada de tratá-las" (SANDEL, 2012. p. 15).

Quanto aos animais, a mudança de paradigma que vêm ocorrendo nos últimos anos, tem ampliado, ainda que lentamente, a perspectiva de que nem tudo pode ser comprado ou vendido. Ainda que não haja unanimidade sobre este ponto, algumas espécies de animais são protegidas por lei e retiradas de práticas comerciais, sendo considerado um crime o seu aprisionamento, sua venda e seu consumo alimentar. Mas isso se dá unicamente por uma razão antropocêntrica, como o interesse em preservar uma espécie exótica ou de interesse científico. Em razão do especismo eletivo, algumas espécies são escolhidas para receber proteção enquanto outras continuam inteiramente disponíveis para satisfazerem aos interesses do mercado.

Ainda que a análise de Sandel não seja tão otimista, pois há cada vez menos coisas que o dinheiro não compre, nós vemos de modo otimista a questão específica do tratamento dos animais e esperamos que, a exemplo do que ocorreu com a abolição do trabalho escravo na economia, haverá uma desvinculação dos animais da lógica de mercado, que poderá ocorrer na mesma medida em que aumentará a desvinculação da sociedade da moralidade especista. Portanto, embora o mercado exerça uma forte influencia sobre a moralidade, corrompendo muitas vezes seus valores e bens, também existe uma influência das mudanças morais sobre o mercado, capaz de levar este último a adequar-se aos novos valores não especistas dos consumidores.

R. Inter. Interdisc. INTERthesis, Florianópolis, v.12, n.1, p.01-15, Jan-Jun. 2015 


\section{CONCLUSÃO}

Como pôde ser observado, a economia e a moral não são plenamente separáveis. Elas se relacionam antes de maneira recíproca, interferindo uma na outra. Ora é o mercado que influencia as decisões e ações humanas de modo coercitivo ou corrompe certos valores e bens, ora é a moralidade que, por sua vez, estabelece limites ao mercado nas esferas da vida humana e da vida animal. Muitas empresas de cosméticos interrompem os testes de seus produtos em animais quando os consumidores buscam comprar apenas produtos Cruelty Free. Outras passam a criar uma linha de alimentos voltados a atender a demanda de consumidores que buscam alimentos que não sejam de origem animal. Empresas do setor da moda passam a trocar suas linhas de couro animal pela de couro sintético. Estes exemplos demonstram que o mercado também se adequa ou até, em alguns casos, é determinado pelos novos padrões morais não especistas, modificando-se para atender uma nova forma de consumo motivada por fatores éticos que levam em consideração os animais não-humanos.

R. Inter. Interdisc. INTERthesis, Florianópolis, v.12, n.1, p.01-15, Jan-Jun. 2015 


\title{
WHAT THE MARKET DOES NOT KILL: AN ANALYSIS OF SPIECIESIST MORALITY AND ECONOMICS
}

\begin{abstract}
In this paper we discuss the relation between morality and economy starting with Michael Sandel's analysis of the moral limits of the market. Sandel investigates how moral values are increasingly being included within the logic of market economy guided by profit. We investigate particularly how the speciesist morality that justifies the exclusion of animals from the moral community is bound to the logic of market, including and keeping nonhuman animals within a system that seeks monetary profit through their exploration and commercialization. We defend that although the economy has a significant influence in determining certain moral practices, the opposite is also true, i.e., morality can also exert an influence on the market and dictate its limits regarding what may or may not be submitted to the logic of economic profit. The overcoming of speciesist morality through ethical proposals to include sentient beings in the sphere of moral actions and to take their interests into account, could - so our conclusion - lead to free animals from the market logic.
\end{abstract}

Keywords: Economy. Speciesism. Morality. Sentience.

\section{LO QUE EL MERCADO NO MATA: UN ANÁLISIS DE LA MORALIDAD ESPECISTA Y LA ECONOMÍA}

\section{Resumen:}

En este trabajo analizamos la relación entre la moral y la economía a partir de la discusión suscitada por Michael Sandel acerca de los límites morales del mercado. Sandel investiga de qué manera los valores morales están siendo cada vez más inseridos dentro de la lógica del mercado económico pautada por el lucro. Más precisamente, investigamos de qué manera la moralidad especista, que fundamenta la exclusión de los animales del ámbito de la comunidad moral humana, está vinculada a la lógica de mercado, insiriendo y manteniendo a los animales no humanos dentro de un sistema que busca lucro monetario por medio de su explotación y comercialización. Defendemos que aunque la economía tenga una influencia significativa para determinar ciertas prácticas morales, también ocurre lo contrario, la moralidad también puede ejercer una influencia sobre el mercado y dictar sus límites sobre aquello que puede o no puede ser colocado dentro de la lógica del lucro económico. La superación de la moralidad especista a partir de propuestas éticas que incluyan a los seres sencientes en la esfera de la acción moral de los seres humanos, considerando, por lo tanto, sus intereses, es capaz de conseguir la desvinculación de los animales de la lógica del mercado.

Palabras clave: Economía. Especismo. Moralidad. Senciencia. 


\section{REFERÊNCIAS}

FELIPE, Sônia. T. Dos Direitos morais aos Direitos Constitucionais: para além do especismo elitista e eletivo. In: Revista Brasileira de Direito Animal. n. 2, ano 2, p. 143-159, jan/jul, 2007.

SANDEL, Michael J. O Que o Dinheiro Não Compra: os limites morais do mercado. Tradução: Clóvis Marques. 4ª . ed. Rio de Janeiro: Civilização Brasileira, 2013.

Tanner Lectures, 1998. What Money Can't Buy: the moral limits of markets. In: The

SINGER, Peter. All Animals are equal. In: REGAN, Tom; SINGER, Peter. Animal Rights and human obligation. 2a . ed. New Jersey: Prentice Hall, 1989, p. 73-86.

Lugano, 2004. - Libertação Animal. Tradução: Marly Winckler. Porto Alegre:

\section{Artigo:}

Submetido em 05.05.2015

Aceito em 03.06.2015 